\title{
The Technical Codes of Online Education
}

\author{
Edward Hamilton \& Andrew Feenberg \\ Simon Fraser University
}

\section{Introduction: A Deterministic Politics of Online Education}

Online education was invented by academics, and at its origin reflected their values and pedagogical conceptions. But they lacked resources for imposing their innovation on a wide scale. University computer centres were often uncooperative, administrations indifferent, and business prospects as yet unimagined. Individual faculty might gain support for small experiments, but online education seemed more a hobby of a few odd champions than a significant advance.

All this changed in the late 1990s, when university administrations realized they faced insoluble budgetary challenges in serving the coming generation of students and meeting the mounting demands from government and industry for a highly educated workforce. In this context, online education was called upon to solve some of the deepest economic, pedagogical, and organisational problems of the university. In solving these problems, however, online education was also expected to transform higher education in a way that would leave no corner of the institution untouched.

Computer and software companies saw a market in this transformation and suddenly online education was on the front page of the newspapers as the Next Big Thing. Those who had worked quietly in the field for the previous fifteen years were generally ignored in the rush to a technological revolution that, it became rapidly clear, was all about money-money to be saved by substituting capital for labour on campus along lines familiar from many earlier de-skillings of crafts and professions-with only secondary consideration given to the pedagogical and professional concerns that guided early experimentation and innovation.

In the late 1990s, online education thus emerged as an object of considerable political contention in the university. It became embedded in a rhetoric of reform which tended to set traditional structures and practices in fundamental opposition to the next evolutionary stage in higher education. The "virtual university" stood as a technological destiny, the logical replacement for the cumbersome, rigid, and anachronistic "traditional" institution. 
In such evangelical discourses, online education was often represented as an inevitable challenge and a transformative force. In the stronger version of this rhetoric, brick-and-mortar universities would vanish, no doubt in a puff of pipe smoke and a rustle of tweeds, to be replaced by the effervescent movement of digital information in global telecommunication networks. The structural transformation of academic labour and the academic profession was depicted as both a necessary pre-requisite for and an inevitable consequence of the increasing technological mediation of higher education.

The zeal with which this evangelical vision was professed is perhaps difficult to remember in a more sober age. ${ }^{1}$ Nevertheless, it was not so very many yeas ago that encomiums on the "death of the traditional university" were being uttered with little caution by university administrators, corporate CEOs, the heads of research organisations, government officials, and even some faculty. Peter Drucker's (1997) prediction that traditional universities would become "wastelands" in the early decades of the twenty-first century was only an inflated version of a claim being made in calmer tones elsewhere. According to some, the virtualisation of the university would mean the replacement of "physical processes with new processes that can be accomplished over networks" (Katz \& Oblinger 2000, 2). For others, the technology heralded the "unbundling of higher education services" with "different providers carrying out different functions: curricular development, delivery of instructional modules, provision of student services, student evaluation, and awarding credentials" (Wallhaus 2000, 22). The intensified division of labour made possible by breaking the faculty's monopoly on education would demote professors to deprofessionalised "content experts," or at least allow universities to "rationalize" their labour practices. One university professor, commenting on and offering admonishment to faculty resistant to online education, stated that

Universities are in the information business, and the information railroad is coming... we would be wise to ask whether the particularly quaint way that we manufacture, distribute and deliver that education will survive the arrival of the information railroad (Wulf 1998, 1-2).

It is this type of rhetoric that early critics of online education responded to and came to equate with the real developmental trajectories of the field despite the wide diversity of actual practice. For critics, the dissolution of the university into digital networks would make possible the further dissolution of the traditional 
social and professional structures in which higher education had been embedded for close to a millennium. Thus, online education became a major focus of debate over the future of higher education. The debate, however, was one in which the question of online education an actually existing socio-technical movement with a complex history became inseparable from the simplistic rhetoric surrounding the technology underlying it. Once "online education" had been solidified as a rhetorical or discursive figure, the debate could be carried out with little detailed examination of ongoing socio-technical developments in the field. Its "nature" was fixed, and conflictual interests polarised around it.

Online education thus appears in one of two registers in debates over educational reform in the late 1990s. One side presents a story of the progressive development of technology as it is applied to the organisation of higher education, leading to pedagogical advances and to the new forms of administration required for the realisation of the technology's full potentials, both pedagogical and economic. Peter Drucker's famous claim, mentioned above, is a much-cited, if extreme, instance of this view, though it has had more recent and more sober-minded proponents as well: "[Universities] will need to transform [to take advantage of online education] or they will die" (Bates 2004). ${ }^{2}$ Here, online education is understood as a concatenation of tools that impose certain adaptations and structural adjustments. The alignment of these changes with particular economic interests is regarded as merely incidental. ${ }^{3}$ Online education is neutralised to the point where any suggestion of a political context disappears behind a façade of technical inevitability.

The other side presents a socio-political account of the dynamics of corporate power in the contemporary university. Online education is seen as a lever of neoliberal reform, an extension to the university of a capitalism that is now digital, global, and knowledge-based. Information technology has supplied capital with a powerful means of integrating and transforming a site of social practice previously independent of markets and economic production. In David Noble's words "...here as elsewhere technology is but a vehicle and a disarming disguise" (Noble 2002, 26). ${ }^{4}$ In this view, online education is reified around political-economic interests that it is claimed, unequivocally, to represent. Commodification, commercialisation, and corporatisation are understood as fundamental dimensions of the technology and its consequences for higher education and the university. 
Both sides of the debate pay particular attention to the way in which technology will, for better or worse, transform the professional structure and pedagogical practices of university teaching. What one group conceives as a search for greater efficiency and accountability, the other sees as the increasing deprofessionalisation (even the automation) of academic labour. What one side praises as greater flexibility for students, the other condemns as an extension of managerial control over instructors. What one side sees as a means of integrating higher education into a rapidly changing information society, the other regards as the death of the critical university and its subordination to commercial interests. What one side interprets as a pedagogical advance, the other criticizes as an attempt to wrestle profit out of an expensive and recalcitrant institution through the commodification of learning.

The problem with these accounts is not that their claims, taken individually, are entirely incorrect, nor that they point to insignificant trends in the university. The problem is the general philosophy of technology underlying both versions of the story. On each side, technology emerges as a fait accompli with which the university must comply or which it must reject out of hand in defence of traditional academic values and priorities. Educational technologies are supposedly uniquely compatible with neoliberalism, which supplies their ultimate meaning and supports the growth of online education as an instance of pure technical development. Both views, then, are based on essentially deterministic assumptions, drawing on a perspective that has been rigorously criticized in both philosophical and empirical study of technology. ${ }^{5}$

This has led to an unfortunate situation in which each account, while sharing an identical spontaneous philosophy of technology, appears exclusive of the other, divided between priorities and values that are imagined to be irreconcilable. One side tends to ignore or dismiss the political-economic climate within which online education has developed, externalising critical claims, while the other depicts technology as a static given, intrinsically biased in favour of capitalism and unresponsive to social pressures and choices. While some recent research has begun to note and respond to this situation, ${ }^{6}$ the debate largely continues to reproduce these polarised and reified terms.

This impasse is in need of redressing from within an alternative philosophical orientation that can widen the scope of critical debate over online education and the restructuring of the university. Critical theory of technology ${ }^{7}$ supplies such an orientation in its emphasis on the dynamics of technological design and 
development as social and political processes. In order to resituate technology in the politics of the contemporary university we will examine the case of an early experiment in educational computer conferencing. In the final sections of this paper we will draw some conclusions from this case regarding methodology and policy in the online education debate.

\section{From Commodification to Communication: Differing Socio-technical Paradigms}

Critical observers of the potential "impacts" of the computer in higher education have, from early on, envisaged it in terms of the commodification of knowledge, the automation - or at least de-skilling - of instruction, and the subordination of education to economic ends. Lyotard, for example, sees the computer reducing knowledge to "quantities of information," and as "rigorously [externalising knowledge] with respect to the knower" (Lyotard 1979, 13). Aronowitz (2000, 155) concurs: in computer-mediated education the student "responds to packaged material," which is prepared by star academics but delivered by a casualised labour force. In Werry's (1999) account, this casualised labour force is replaced by actors, presumably because once the content is supplied, its delivery is best handled by real experts. Noble (2002), too, follows this line, depicting online education as successor to the commodified educational products and Taylorised labour process of early twentieth century correspondence schools. The critics agree: computer mediation means a reduction of education to information, of faculty to deprofessionalised "content providers," and of the university to a site of commercial information production.

Were these conclusions based on thorough empirical study, they could be challenged only by equally thorough studies. Indeed, the empirical reality of online education is a great deal more heterogeneous than the critical discourse, in its fear of a monolithic technical juggernaut, has allowed. Unfortunately, critics of online education have largely failed to capture the real situation. Rather, they have tended to argue from the numerous historical precedents for the process they believe themselves to be observing. Indeed, similar critiques have appeared throughout the history of educational technologies and media, from Plato's attack on writing, to the fear in the 1950s that TV would usher in the era of "the automatic student and the robot professor" (Plato 1973; Smith 1958).

What Plato has to say about writing is not much different in substance from later critiques of educational broadcasting and computing, centring as it does on the 
way in which the new medium offers a static embodiment of knowledge and a vehicle for distributing it independent of social relations, contexts, and structures. Plato was clearly thinking of the educational application of the computer-or perhaps the Internet-when he prophesied that "students will receive a quantity of information without proper instruction" (Plato 1973, 96). "Proper" instruction requires dynamic contexts of co-presence. As Lyotard later approaches the computer, so Plato approaches writing as a means of "externalising knowledge from the knower." Both critiques are rooted in a formal conception of how writing or the computer act on information - the technologies are conceived as essentially representational in nature, and it is as such that they are understood to relate to and remodel the education process according to a narrow pedagogy of information delivery and acquisition (Blake \& Standish 2000; Robins \& Webster 2002).

Early educational applications of the computer such as computer assisted instruction (CAI) clearly reflect just such a reduction of education, and support both the commodification of content and an agenda of automation. Designed as basic drill-and-practice tools, CAI systems draw upon the affordances granted by the pre-network era computer as a stand-alone information processor-its capacity to record, store, analyse, represent, and organise information. The system presents a specific content and the student "interacts" with the technology by responding to prompts that cue movement through it. The system regulates the student's progress by intermittently evaluating performance on standardised quizzes (Distefano 2004; Hiltz 1994). The social relations of education are here broken down along functional lines. Social interaction is replaced by interaction with technology and the static content it delivers, and the producers of knowledge are separated from the learners they traditionally encounter in the classroom.

This configuration of the computer in the education process is not limited to "classic" CAI, though the latter represents the most clearly automated form of computer-mediated education. The CD-ROM courseware disparaged by Noble reproduces a similar model, and offers education in a similarly commodified form alienated from human interaction and dialogue (Noble 2002). Contemporary learning management systems (LMS), such as WebCT, while they are not designed to support full automation, can and sometimes have been appropriated for deprofessionalised forms of computer-mediated education on the basis of an interpretation of the Internet as means of distributing computerized representations of knowledge. In that context, the computer is configured as an 
information delivery device, and the educational process is divided into discrete production tasks. The work of the teacher is partly delegated to the system, and the remaining human tasks, such as information gathering, performance evaluation, and certification, can be handled by low paid clerical employees or part-time tutors.

It is easy to see why critics might disparage this version of computer-mediated education as a commodified pedagogy of information delivery. Reduced to information, education seemingly no longer requires its traditional social mediations - the physical classroom, the university as an institution, or the professional teacher. It can be organised like a process of industrial production of commodified goods consumed by isolated individual learners. It is also easy to imagine who might find such a redefinition of education attractive. It is a short step from a pedagogical model of information delivery to an industrial model of information production, and a commercial model of information marketing and consumption. The transformation of education into a product promises a new revenue stream for economically beleaguered universities. In economic terms this product resembles CDs or software, the marginal cost of which declines rapidly with the number of units produced. A popular "brand," such as MIT, might become a sort of educational Britney Spears, milking "platinum" courseware for big profits. The university finally has a "business model." University administrators eager to cut costs can find common ground here with commercial interests seeking access to the multi-billion dollar education market.

An economic logic which views education as simply another variety of "ecommerce," with knowledge as a commodity to be packaged, marketed, and sold, appropriates the available technologies as a system for distributed representation. If these technologies can divest higher education of a need for classrooms, physical plant, and teachers, they can also reduce the operating costs of serving a fast growing student population. While often disguised behind claims of improved quality, accessibility, and a more flexible "student-centred" approach, the economic motives behind this pedagogical model are strong enough to tar educational technologies irredeemably with the brush of Mammon. On the university's economic ledger pedagogical niceties are incidental to cost-efficient delivery of pre-packaged, standardised courseware, and access to globally dispersed learner markets. ${ }^{8}$

A pedagogy based on commodified, automated, decontextualised information delivery, the technologies of distance education, and the prevalence of an 
economic discourse of higher education have been so tightly interwoven as to enable a critique of the one to imply, even stand in for, a critique of the others. Even where networked educational technologies are concerned-technologies that can and do support human interaction - the tendency has been to understand them in terms of the representational capacities of the computer rather than as redefining or resituating these capacities in the context of new forms of mediated communication.

But it is precisely this latter potential that opens the computer up for appropriation within pedagogical (and political) frameworks other than the delivery of information commodities, and so raises the possibility of directing the technology, and online education as a movement, away from a formal replication of teacher functions in a strategy of automation and deprofessionalisation. Networked learning can be based on the computer's relational rather than its representational capacities. The assumption that online education is equivalent to the organisation, presentation, and delivery of information ignores a vital impact of the convergence of telecommunication and computing, namely, the creation of an environment for social interaction between geographically and temporally distant users. While this might seem an obvious point, it has great significance for the politics of online education. A historical case may serve to clarify this significance.

\section{Computer Conferencing at WBSI $^{9}$}

In the early 1980s, while CAI was still the dominant mode of educational computing, a number of academically-based experiments tested educational applications of asynchronous, text-based computer conferencing. Successful online discussion groups of a more general, voluntary, and sometimes random sort had emerged prior to this on such services as The Source and CompuServe. Educators critical of the information delivery model of CAI hoped to draw upon the capacity of conferencing systems to support group communication in order to realise a model of online education based on a dialogic pedagogy (Feenberg 1993; Kaye 1989; Kerr \& Hiltz 1982; Mason \& Kaye 1989). Among the early experiments were a series of teacher-training courses at the New Jersey Institute of Technology, some Adult and Continuing Education courses at the New York Institute of Technology, the New School's Connected Education program, and an experiment in mass education using computer conferencing at the Open University in the UK. The first organised online education programme, however, was the School of Management and Strategic Studies (SMSS), which opened in 
January of 1982 at the Western Behavioural Sciences Institute (WBSI) in La Jolla, California.

The SMSS was a two-year executive education program dedicated to fostering critical humanistic dialogue around issues and problems of information societies in a rapidly globalizing economy. Participants came together at week long biannual meetings at the Institute, but otherwise their only link with the program and one another was the Electronic Information Exchange System (EIES) - the conferencing system employed in the SMSS. The program was divided into four semester-long courses, bracketed by the face-to-face meetings, with each course broken down into month-long seminars moderated by university faculty from all over the US. There were no assignments, no grades, and no certification-and yet despite the lack of the usual external motivations for study, the SMSS grew from a program with 8 initial participants, all but one in the US, to over 150 participants from two dozen countries around the world. So successful was the SMSS that it was ranked in Harvard Business School's top 5 executive education programs (Meeks 1987; Gottschalk 1983). ${ }^{10}$

While the success of an asynchronous, globally distributed online education program might appear in hindsight merely to confirm what everybody already knew about the "impacts" of new communications technologies on educationincreased access and quality, user enthusiasm, and the potentials of "virtualisation"- the SMSS owed less to the abstract properties of new technologies than to the way in which their affordances and limitations were interpreted through specific pedagogical and social values and actively appropriated. WBSI's faculty and staff realised from the start that computer conferencing was not a means of information delivery but a context for social interaction, communication, and dialogue. However, since the medium was untried in education, no models for conducting an educational computer conference existed. Moreover, conferencing systems had not been designed with specifically educational applications in mind, but according to generic definitions of the communication process (Hiltz 1994; WBSI 1987). Faculty, staff, and participants in the SMSS had to invent online education as they went along, negotiating between various notions of alternative pedagogy and the affordances and constraints of the conferencing medium.

Distributed, asynchronous, text-based communication is the primary mode of interaction afforded by computer conferencing. Today there is a standard discourse for describing the advantages of this mode of interaction: flexible 
anytime/anywhere learning, increased time for formulating considered contributions, egalitarian communication in the absence of visible status markers, and so on. But in the practical contexts of the early experiments, these features of computer conferencing bore an ambivalent relationship to the education process. Distribution and asynchronicity also meant the absence of a ready-made physical context for learning, and the devaluation of passive forms of participation that are perfectly legitimate in such contexts, where visible co-presence enables the easy flow of tacit communication. The verbal cues and situational norms that contextualise interaction in face-to-face settings are absent in text-based communication, making it awkwardly opaque and even intimidating for new users (Feenberg 1989). The ambivalence of these formal features of the technology raised a number of pedagogical challenges for faculty, staff and participants alike.

In CAI, learning is coded in the prescriptive structure of the system itself as a shell for organising a content and for evaluating student performance. Most contemporary learning management systems similarly provide a structure for the representation and acquisition of content and the configuration of tools and applications. In computer conferencing, by contrast, there are no pre-determined prescriptions for learning at all - the system provides a structure for interaction and basic tools to facilitate communication, but no more. Conferencing systems do not replicate teaching functions, nor do they supply an explicit pattern for focussed, cumulative, or directed engagement with content - central elements of learning. There is no content, as far as the system is concerned, apart from the participants' messages. However, regardless of the pure potential of the systems, interaction is by no means a given in the absence of technical prescriptions or social norms of participation.

Where a limited type of human-machine interaction is simply imposed by CAI, human to human interaction is a very real problem in computer conferencing-it is not pre-determined or prescribed technically, but has to be actively achieved. And, as was quickly discovered at WBSI, it had to be achieved in the absence of precedents: at first neither teachers nor students had ever been in an online classroom before. How do you achieve interaction, participation, and focused dialogue - in a word, education - in an environment in which there are no explicit social norms, in which visual cues are absent, and in which none of the participants are together in the moment of interaction? Whereas CAI systems answered these questions by delegating teaching functions and roles to the machine, at WBSI they were answered by communicative strategies. These 
strategies focused primarily on the development of techniques of moderating online discussion.

Arriving at these techniques was not an easy process. Two pedagogical approaches were tried in the early weeks of the first session of the SMSS. One approach was rooted in a belief that the open communication structure of computer conferencing required a "low-impact" moderator. It was presumed that student interest, independent of the conferencing context itself, would drive discussion as it had in other non-educational online forums, and that the provision of a space for communication would suffice to generate focussed and meaningful interaction. Students, having completed a reading assignment, were asked to respond to the readings on the basis of very general questions. The questions were accompanied by a fleeting formal introduction to the course, the extent of which was "Greetings! Here we go." No context or background was supplied through which participants could understand how they might engage substantively in discussion. No norms were proposed through which the participants could understand their roles and responsibilities in this strange environment. And in the absence of the pressures of co-presence there was no particular compulsion to engage at all. Understandably, little participation resulted.

The other approach came from the opposite direction, assuming that the "emptiness" of the computer conferencing environment needed to be filled with content to which students could react. A series of lengthy introductory messages, analogous to a lecture, was sent out detailing the substantive focus of the seminar, and followed up by a set of challenging and thought provoking problems to which participants were invited to respond. Whereas the "lowimpact" approach did little to defuse the anxiety provoked by the blank computer screen, this "high-impact" approach increased the presence of the moderator to such an extent that it left little room for engagement and participation. As a consequence, it inadvertently transformed the conferencing system into yet another vehicle for delivering content rather than facilitating discussion. Again, little active participation followed from this approach.

Unlike interest-based discussion forums, educational computer conferencing begged for the strong, active presence of a live teacher employing a selfconscious pedagogy. Participation was a function of the moderator's ability to both achieve and invite presence, to maintain coherence and direction, and to contextualise, both intellectually and socially, a highly ambiguous 
communication environment. The moderator had to take on contextualising, prompting, synthesising, and facilitating functions and an active leadership role, in such a way as to provide enough structure to engage participants and enough openness to admit them into dialogue (Feenberg 1989; Kerr 1984). Providing context and background, establishing the norms and expectations for interaction, outlining a program and a set of goals, and monitoring the progress of participants - standard dimensions of teaching in the off-line world-were thus reinterpreted in the conferencing medium as a means of facilitating and sustaining educational interaction.

But contrary to a familiar division between "process" and "content," the moderator could not carry out these organisational functions without being an expert in a field. Prompt responses to student questions and contributions were necessary in order to sustain the flow and coherence of dialogue in a context which tended towards fragmentation. But in the SMSS the dialogue itself consisted of humanistic inquiry into philosophical, social, and political-economic issues, as well as the historical and cultural backgrounds of emerging information societies. This called for an ability on the part of the moderator to evaluate and synthesise abstract concepts, provide historical background and contexts, and survey arguments within a field of inquiry. ${ }^{11}$

WBSI faculty soon realised, however, that here expertise bore a different relation to the educational process than in their classrooms. In order to maintain a coherent and directed flow of dialogue and a high level of participation, the synthetic, contextualising, and reflective activity of the moderator had to be more "punctual" than persistent, but no less incisive than in traditional educational contexts. Providing background and delineating the scope of a problem to be explored, the moderator needed to guide discussion based on the contributions of the participants themselves that served to contextualise how subject expertise was brought to bear. Expertise took on a quality of responsiveness in conferencing that it does not have in information-delivery models of computer-mediated education. With the computer in charge rather than a teacher, expert knowledge is programmed in before the educational process actually begins and students simply respond to it as an unalterable context. Far from playing out an agenda of automation and commodification, however, WBSI's model of online education innovated an active social role for the instructor in response to the specific constraints and affordances of the conferencing medium. 
So far our discussion of the communicative functions of computer conferencing at WBSI seems to re-inscribe the traditional antinomy of human and machine. But this cliché does not in fact describe the evolution of the WBSI experiment. It soon became obvious to the group that created the SMSS that they would also have to reinvent computer conferencing if their enterprise was to succeed-to engage directly, that is, in the process of technical innovation. The communicative functions of moderating needed to be accompanied by the development of technical features that could support both the functions themselves and WBSI's pedagogical model. This recognition arose from the problems encountered in using a generic communication technology for specifically educational purposes.

The generic interpretation of communication in conferencing systems failed to take account of how communication differs across social settings. Communication within educational contexts is clearly conducted with different purposes, expectations, roles, values, and norms than is dinner-table conversation within the family, debates at political meetings, or discussions among hobbyists about their hobbies. At the very least, CAI came with a model, however impoverished, of how education took place, assigning roles, norms, and expectations in a coherent manner. Conferencing did not. The social and pedagogical functions of moderating at WBSI answered to, and in part derived from this situation. But they also acted as a framework within which certain design features became desirable, and on the basis of which additional features could be innovated.

These features could be as simple as an ability to track individual participants' progress through the conference, allowing the moderator to better facilitate the conversation on the basis of a clear view of everybody's location within it (WBSI 1987). They could be as complex as a subject indexing feature enabling both participants and moderators to follow different thematic threads and to weave these threads together at appropriate moments in summary comments useful for keeping the conversation on track (Feenberg 1989). Experiments at WBSI with this latter feature failed for lack of sufficient computing power, but later inspired the TextWeaver project discussed in a later section of this paper. Social roles and practices did not develop out of the prior presence of these features. Rather the features were seen as desirable from within the purview of a particular social practice and pedagogical model. 
Another major problem with early conferencing was the complexity of the user interface. It required a page of instructions just to sign on to EIES; and once online, the user was faced with lengthy sets of commands for operations as simple and taken-for-granted as writing, editing, quoting, sending and receiving, reading messages, printing, and attaching documents. The so-called "quick reference card" for EIES was 16 pages long (NJIT 1986). The complexity of the system, however, was of a piece with its flexibility - in order to achieve as open and generic a communication environment as possible, designers merely added menus and command strings, to the point where flexibility seemed to reflect the needs and competences of a narrow stratum of technical designers and what came to be called "computer geeks" rather than students and teachers. The memorisation of non-intuitive command codes for the performance of intuitive social acts set a high bar for communication.

WBSI addressed this situation through the development of an original software application: a user-interface for educational computer conferencing called Passkey (WBSI 1987; 1986). Similar to Web browsers, Passkey was designed as a simplified command interface layered over the more complex communication structure supplied by the conferencing system. Its effect, like the Web browser's for the Internet, was to make the process of online communication more accessible to lay users, obviating the need to rely upon an abstruse set of commands for conducting communication online. Designed with the experience of both moderators and participants in the SMSS conferences in mind, Passkey represented a technical expression of the social, pedagogical and programmatic framework developed over the first four years of the program. Once again, the case exhibits not acquiescence to a set of given technical prescriptions, but the adaptation of technology to the needs of a specific user group.

The desire to enact a dialogic pedagogy, the development of social rather than technical delegations in response to technical constraints, and the undertaking of technological development in response and deference to local social values and expectations tells a much different story of online education than is often portrayed in mainstream debates today. One reason for this difference lies in the proximity of both programmatic and technological development to the contexts of actual educational practice. Automation and commodification did not play as agendas in the SMSS, not only because the technology could not easily support them, but because the interests of instructors were directly present in the design and development contexts. The automation of certain moderating functions was suggested at NJIT, and implemented as yet another menu option, on the 
assumption that participation could most easily be achieved by building in technical features that would require it (Hiltz 1982). If taken in that direction, the technology might have developed to support a similar agenda as informationdelivery oriented CAI systems. But it was in providing an alternative to those systems that WBSI largely understood its work.

All in all, dynamic processes of negotiation and development between technical and social factors not only yielded an alternative model of online education, but in the present context they also open up a range of questions for the critical politics of online education, questions that need to be addressed less in terms of the formal properties of technologies as causative agents, and more in terms of the impact of social contexts of design, development, and pedagogical practice.

\section{A Revised Politics of Online Education}

Educational technologies only gain definition, functionality, and value in the framework of the pedagogical models they instantiate, the forms of social relationship they construct, and the educational goals they are applied to achieve. The technology only "works" within that model, those relationships, and those goals, which supply a set of guidelines for what education in general is. On an abstract, formal level, of course, it could be said that technologies like CAI, CDROM courseware, or content-based online education "transform" education according to a pedagogical model they in a sense "possess." However, this model itself has its origins not in some abstracted technical realm, but at the point where pedagogical, social, and institutional values articulate with design principles, processes, and parameters - the point at which social values and choices come to be translated into technically rational design features. ${ }^{12}$ Indeed, the design of technologies is predicated on a prior definition of the situation to which the technologies are to apply. Education must be defined in a functional, social, and organisational sense before a technology can be developed to support it. The technology may embody a pedagogical model that carries certain political implications for society or career consequences for professional educators, but it only does so through an iterative process through which pedagogical assumptions, values, and roles are delegated to technical systems.

Critical theory of technology calls this background of values, assumptions, definitions, and roles that guides technological design the "technical code" (Feenberg 2002; 1991). Technical codes define a framework of technical decision-making within which certain choices appear rational. These codes are a 
function of the delineation and circumscription of technological development and design by particular social groups to which the ultimate form of the technology is relative. The technical code of online education is relative, then, to the interests, assumptions, and values of the actors who are engaged in the design and development process, and who are thus positioned as powerful interpreters of the technology and the social forms it mediates.

CAI, for example, is not simply a logical derivation from the abstract properties of the computer. It is the product of an interpretation of education which valorises the representational affordances of the computer and directs development towards automated and commodified forms. Computer conferencing, as the WBSI case shows, opened a completely different interpretive field for computer-mediated education in highlighting the functionality of the computer as a communications device. The alternative pedagogy developed at WBSI was not so much the result of the formal properties of computer conferencing as an appropriation of those properties. Conferencing's formal ambivalences with respect to education were addressed at WBSI through both social and technical adaptations aimed at realising an active, dialogic online pedagogy. Automation was never an option, not only because technical limitations at that early date precluded it, but because it was never a value for the developers of the SMSS program. It was incompatible with the technical code out of which WBSI's model of online education emerged.

Computer conferencing and CAI, then, are not just two different uses of the same technology, but supply two completely different paths for the educational appropriation of the computer. They draw upon and support two completely different pedagogical models. They delegate interaction in education in completely different ways. And they operate on two completely different dimensions of the social process of education. Automation and commodification, far from being inevitable consequences of online education, must be understood as contingent outcomes whose realisation depends on a particular configuration of the technology and a particular set of pedagogical choices. Here, as elsewhere, the crucial philosophical and political questions to be asked are: what does the technology stand in for in the educational process, how is it involved in delegating functions across that process, and how is a field of social interests delineated to encourage one iteration over other possible ones?

In information-centric iterations of computer-mediated education such as CAI the technology is designed to stand in for the teacher, to enable the technical 
performance of the functions of human professionals. It is this that aligns it with a program of automation. Communication-centred models of computer-mediated education present a very different scenario. Here the technology stands in for the classroom as an environment for interaction, dialogue, and the formation of community. Rather than taking on a functional role within the educational process, it provides a more or less flexible structure for the negotiation of familiar social roles. Functional delegations are not simply built into the technology, but are actively configured out of a combination of social and technical options that, as in the case of the SMSS, include a role for the professional teacher.

Technologies, educational or otherwise, do not autonomously transform the social contexts into which they are introduced, though their influence in giving shape and substance to those contexts is considerable. Certainly writing transformed the process of learning, but it did not replace dynamic interaction with static information-gathering, as Plato predicted. Over the centuries, educators and students have managed to devise ways of situating writing within interactive social processes. Writing has added its capacities as an information technology to the communicative processes of teaching and learning in ways now so obvious and taken-for-granted that they are barely noted. Networked computing also provides a powerful means of organising, representing, and transmitting information, but to limit it to these capacities is to sub-optimise its potential as a communications medium. The integration of the technology into education is, however, ongoing, and its ultimate form is not yet decided. There is still time for intervention and re-direction in accordance with academic interests and values. Whether a positive evolution of the technology will emerge will depend, in part, upon the ability of academics themselves to move beyond the static oppositions and absolute positions that have characterised debates in the field.

\section{Questions of Educational Technology}

What are the implications of this analysis for technical design? The "interpretative flexibility" of computer networking is very great. It was easy for new actors with different goals to take over the original project of online education and to redefine it to mean something new. Very quickly, this new conception of the field was reflected in the design of the new "learning management systems" which have spread across North American campuses. 
Online education was finally successful but in a form unrecognizable to its original inventors.

These learning management systems generally emphasize the representational rather than the relational potential of networked computers. Often, but not always, a web forum, equivalent to the computer conferences of old, is included in the product but given little attention by trainers preparing instructors to use the new technology. The interpretation of online education resisted by Noble and others was effectively inscribed in its technical code to the extent that this was technically and politically feasible. In response, resistance to online education has tended to accept this code as inevitable, mistaking a particular social design for the nature of the technology itself.

The WBSI case takes on its full significance against this background. True, it never achieved the widespread usage of the current systems. But it represents an existence proof of the alternative. It demonstrates the possibility of another line of development that would emphasize relational potentials rooted in traditional pedagogical conceptions shared by most faculty rather than the budgetary concerns of administrations and commercial strategists. The single most important constraint that flows from this alternative line of development is small classes, manageable by a living professor, rather than huge audiences or markets for semi-automated educational "products." In this form online education must defend its value on a pedagogical basis because it cannot significantly contribute to cheapening education or selling educational products. There is no "business model" for learning as traditionally conceived, even when the classroom is virtual.

This line of development, too, is inscribed in a technical code. Insofar as the movement for open source educational software depends primarily on faculty input and support, this technical code is likely to emerge as its agenda. To illustrate this point, we will briefly describe two initiatives in this field.

The primitive web forums in most learning management systems have no educational features but are simple copies of old newsgroup software. Andrew Feenberg, one of the founders of the SMSS, has developed an open source alternative called TextWeaver. This is a conferencing application that includes features specifically designed for education that enhance online discourse by facilitating quotation from multiple messages and enable students and teachers to create and assign their own individual keywords for organizing the discussion 
archive. $^{13}$ These features serve specific pedagogical goals such as encouraging student-to-student interaction and periodic summations by the teacher.

On a much larger scale, the Sakai Project ${ }^{14}$ is a $\$ 6.8 \mathrm{M}$ community source software development project founded by the University of Michigan, Indiana University, MIT, Stanford, the uPortal Consortium, and the Open Knowledge Initiative with the support of the Andrew W. Mellon Foundation. Sakai is, among other things, creating an open-source learning management system, the first version of which was released in July 2004. In addition to providing open source online education tools and applications, Sakai is also developing a "Tool Portability Protocol" which will provide a framework for universities to develop and share software. While the open-source license of Sakai does not prevent the commercialisation of its software, it ensures that the knowledge base upon which such developments are made remains open and sharable. Universities are thus able to retain a much greater level of control over development, adoption, support, and implementation than is possible with commercial systems. This project is perhaps the largest and most promising effort to free online education software development from commercial control, both for cost savings and, more importantly, to insure that faculty have significant input into the design of the software environments they will employ in their work.

The current state of online education is deeply ambiguous. Administrations have had to temper their ambitions as they discovered that the technology was not capable of delivering on the promise of cost-effectiveness without severely degrading educational quality. This was a prospect resisted by both faculty and students, notably in the California State University System where demonstrations at the state legislature and resolutions by faculty senates blocked a corporate sponsored attempt to "wire" the campuses. But before this realization had sunk in, universities invested millions in the infrastructure of online education. The basic software acquired in this context and used now on most campuses retains the representational emphasis reflecting the automating agenda of the commercial vendors who originally drove this process with unrealistic promises.

Meanwhile, faculty often, if not always, appropriate the available systems for a familiar pedagogical practice that combines representation of content, the online equivalent of the textbook, with the active use of a web forum, the online equivalent of classroom discussion. This is precisely the sort of thing envisaged at WBSI twenty years ago. But these practices are not often supported by corresponding reductions in teaching loads and class sizes to render the 
interactive online pedagogy truly comparable with classroom teaching in terms of burden and effort. This confusing state of affairs may slowly give way to a satisfactory synthesis if open source initiatives are successful and faculty organizations aggressive. This is the outcome towards which we should work rather than resisting online education as such.

\section{Conclusion: Policy and Design}

The essential question to ask in a revised politics of online education is whether the technology will work to facilitate the transmission of static information, fostering standardised modes of interaction between human users, machines and commodified knowledge, or whether the technologies and online programmes can be rooted in an essentially social ideal of education, extending and enabling new forms of mediated interaction. Technology could potentially support either one of these programmes. But, as outcomes, they are in no sense given prior to specific appropriations within particular social settings.

Struggles over technological change take place in social contexts that have their own historical dynamics, and that provide their own affordances for action, authority, and intervention. The university is no exception. It is a complex social institution organised around an administrative core whose relative power has increased significantly over the past half century, but in which there is still a strong tradition of professional self-governance and participatory decisionmaking. Despite the growing discretionary power of both administrative bodies and state/corporate interests, faculty and students still have some power in the institution and can intervene in institutional change. Policy developments with respect to educational technologies and distance education show that the critique of online education can and must include an account of interventions through the community-based structures of the university and professional associations. These latter have acted for the incorporation of faculty interests into online education. They are also important sites for the enactment and analysis of an alternative critical politics of online education.

The American Association of University Professors (AAUP) and the Canadian Association of University Teachers (CAUT) have issued position statements on online and distance education that act as an important basis for local faculty intervention in the appropriation of educational technologies. ${ }^{15}$ In the case of the CAUT, these statements address issues of commercialisation, privatisation, and deprofessionalisation. By framing their position with respect to particular social 
issues, CAUT establishes a basis for the alternative development of online education, and promotes critical engagement by local institutions in the appropriation of educational technologies.

The AAUP statement on distance education is framed in terms of the disjuncture between academic policies governing more traditional means of distance education and networked technologies. Recognition that the new technologies have the capacity to do something fundamentally different from the old correspondence school model and CAI suggests that they ought to be designed to better conform with basic academic values and priorities. Academic freedom, free access to information, freedom of teaching, intellectual property rights, and so on are central to the position-statement and outline clearly the need to embed new technologies and online programmes in traditional professional and institutional interests and structures. The responsibility for developing online education is situated within the academic community as a whole, with recognition that new technologies must be integrated into education through the normal academic channels.

But do these position statements have any impact on local policy? We have not surveyed the broad spectrum of institutions adopting the new technologies, but here at least is a significant example of the sort of developments we hope are widespread. San Diego State University's faculty senate has developed a comprehensive distance education policy that addresses the issues of automation, deskilling, and commercialisation. ${ }^{16}$ The policy grounds the development of distance education in the traditional mission, governance and decision-making structures, and value frameworks of the university. This policy mandates that distance education technologies be evaluated according to traditional pedagogical and professional principles, and that relationships with external organisations providing courseware and technology be open to scrutiny by faculty committees. Most importantly, the policy requires that both educational technologies and distance programmes be organised in a way that respects faculty autonomy, academic freedom, and intellectual property. The policy also contains guidelines for employment of adjunct and part-time non-tenured faculty, and thus engages directly and proactively with one of the main points of political contention in debates over online education - its role in the deprofessionalisation of university teaching.

These policies and position statements provide a framework for the development and implementation of online education and educational technologies within the 
context of the values, norms, and expectations that typify universities as professional organisations. They strengthen the alternative technical code of online education worked out in early computer conferencing by placing that code within the larger institutional and organisational frameworks of universities and professional associations. And they address the concerns of online education's most vehement critics, appropriating critical discourse into socio-technical decision-making.

In the wake of the general disappointment with the exaggerated claims made for online education, there is now wide latitude for faculty intervention and participation in shaping the terms on which it will impact the academic labour process, the division of academic labour, and ownership of intellectual resources. It is now clear that online education will not destroy the university as we know it. What it will become will be determined ultimately by the politics of the very institution it promised to replace only a few years ago.

\section{References}

AAUP. 2004. "Academic freedom and electronic communications. Report of Committee A on Academic Freedom and Tenure." (http://www.aaup.org/statements/REPORTS/04AFelec.htm).

1999. "Statement on distance education. Special Committee on Distance Education and Intellectual Property Issues," http://www.aaup.org/statements/Redbook/StDistEd.HTM.

Aronowitz, S. 2000. The knowledge factory: Dismantling the corporate university and creating true higher learning. Boston: Beacon.

Bates, A.W. 2004. "Why universities must change: The challenge of eLearning." 9 June. Simon Fraser University. Jossey-Bass.

2000. Managing technological change: Srategies for university leaders. San Francisco:

Blake, N. \& Standish, P. 2000. Enquiries at the interface: Philosophical problems of online education. Oxford: Blackwell.

Callon, M. \& Latour, B. 1981. "Unscrewing the big Leviathan: How actors macro-structure reality and how sociologists help them to do so." In Advances in social theory and methodology: Toward an integration of micro- and macro-sociologies, edited by K. Knorr-Cetina and A.V. Cicourel, 277-303. London: Routledge \& Keegan Paul.

Castells, M. 2000. The rise of the network society. Vol. I, The information age. Oxford: Blackwell. CAUT. 2004a. "Policy statement on academic freedom. Academic Freedom \& Tenure Committee." December 2002, at http://www.caut.ca/en/policies/academicfreedom.asp. 
. 2004b. "Policy statement on distance education," at http://www.caut.ca/en/policies/distance education.asp.

Cornford, J. \& Pollock, N. 2003. Putting the university online: Information technology and organisational change. Philadelphia: Society for Research into Higher Education \& Open Univ. Press.

Distefano, A., Rudestam, KE. \& Silverman, R.J., eds. 2004. Encyclopaedia of distributed learning. Thousand Oaks: Sage.

Drucker, P. 1997. "Seeing things as they really are." Interview by Robert Lenzner and Steven S. Johnson, Forbes 159 (5): 122-129.

Duderstadt, J.J. 1999. "Can colleges and universities survive in the information age?" In Katz \& Associates. Dancing with the devil: Information technology and the new competition in higher education, 1-25. San Francisco: Jossey-Bass, Educause \& Pricewaterhouse Coopers.

Feenberg, A. 2002. Transforming technology: A critical theory revisited. Oxford: Oxford Univ. Press.

1999a. Questioning technology. London: Routledge.

1999b. "Distance learning: Promise or threat?" Crosstalk (Winter), at http://www-rohan.sdsu.edu/faculty/feenberg/.

1999c. "Wither educational technology?" In Peer Review 1:4 (Summer), at http://www-rohan.sdsu.edu/faculty/feenberg/peer4.html.

1995. Alternative modernity: The technical turn in philosophy and social theory. Berkeley: Univ. of California Press.

1993. "Building a global network: The WBSI experience." In Global networks: Computers and international communication, edited by Linda M. Harasim, 185-197. Cambridge, MA: MIT Press.

1991. Critical theory of technology. Oxford: Oxford Univ. Press.

1989. "The written world: On the theory and practice of computer conferencing." In Mindweave: Communication, computers and distance education, edited by R. Mason and A. Kaye, 22-39. Oxford: Pergamon Press.

Galan, N.V. 2001. "Throwing down the gauntlet: the rise of the for-profit education industry." In B. Lewis, R. Smith and C. Massey. The tower under siege: Technology, power, and education, 11-28. Montreal-Kingston: McGill-Queen's Univ. Press.

Gottschalk, E.C. 1983. "California institute uses 'teleconferences' to teach business strategy, computer use." The Wall Street Journal. 10 February. 
Hiltz, S.R. 1994. The virtual classroom: Learning without limits via computer networks. Norwood, NJ: Ablex.

1982. “Comment CC14: 21 February, 1982.” In E. Kerr. Computers in education. Unpublished computer conference transcript. NJIT: EIES, C303.

Inglis, A., P. Ling and V. Joosten. 2002. Delivering digitally: Managing the transition to the knowledge media. $2^{\mathrm{d}}$ ed. Open and Distance Learning Series. London: Kogan Page.

Katz, R. \& D .Oblinger. 2000. The 'e' is for everything: E-commerce, e-business and e-learning in the future of higher education. Educause Leadership Strategies, no. 2. San Francisco: Jossey-Bass, Educause \& Pricewaterhouse Coopers.

Kaye, T. 1987. "Computer conferencing for distance education." Nuove tecnologia e vita quotidiana in Europa. 12-14 November. Bologna.

Kerr, E.B. 1984. "Moderating online conferences. Computerised Conferencing \& Communications Centre, Research report \#20.” Newark, NJ: New Jersey Institute of Technology.

Kerr, E.B. and S.R. Hiltz. 1982. Computer-mediated communication systems: Status and evaluation. New York: Academic Press.

Latour, B. 1999. “On recalling ANT.” In Actor network theory and after, edited by J. Law and J. Hassard. Sociological Review Monograph. Oxford: Blackwell.

1995. "Mixing humans and nonhumans together: The sociology of a door closer." In Ecologies of knowledge: Work and practices in science and technology, edited by S.L. Star, 257-277. Albany: SUNY Press.

1991. "Technology is society made durable." In A sociology of monsters, edited by J. Law, 103-131. Sociological Review Monograph, no. 38. London: Routledge.

Levidow, L. 2002. "Marketising higher education: Neoliberal strategies and counter-Strategies." at http://www.thecommoner.org.uk.

Lewis, B., R. Smith, and C. Massey. 2001. The tower under siege: Technology, power, and education. Montreal/Kingston: McGill-Queen's University Press.

Mason, R. 1988. "The use of computer-mediated communication for distance education at the Open University.” Occasional paper. September, 1988. Buckingham UK: Open University.

Mason R., and A. Kaye., eds. 1989. Mindweave: Communication, computers and distance education. Oxford: Pergamon.

Meeks, B. 1987. "The quiet revolution: Online education becomes a real alternative." Byte (February): 183-190. 
Moll, M., ed. 2001. But it's only a tool! The politics of technology and education reform. Proceedings. Educational Research Association (AERA), Montreal, 1999. Ottawa: Canadian Centre for Policy Alternatives.

., ed. 1997. Tech high: Globalisation and the future of Canadian education. Ottawa: Canadian Centre for Policy Alternatives \& Fernwood Publishing.

Naidu, S., ed. 2003. Learning and teaching with technology: Principles and practices. London: Kogan Page.

NJIT. 1986. "EIES quick reference card.” Unpublished computer conference transcript.

Noble, D. 2002. Digital diploma mills: The automation of higher education. Toronto: Between the Lines Press.

Pinch, T. and W. Bijker. 1989. "The social construction of facts and artefacts: Or how the sociology of science and the sociology of technology might benefit each other." In The social construction of technological systems: New directions in the sociology and history of technology, edited by W.E. Bijker, T.P. Hughes, and T. Pinch, 17-50. Cambridge, MA: MIT Press.

Plato. 1973. Phaedrus and Letters VII and VIII. Trans. W. Hamilton. London: Penguin.

Readings, W. 1996. The university in ruins. Cambridge, MA: Harvard UP.

Robins, K. and F.Webster. 2002. The virtual university? Knowledge, markets and Management. Oxford: Oxford Univ. Press. Routledge.

1999. Times of the technoculture: From the information society to the virtual life. London:

Schiller, D. 1999. Digital capitalism: Networking the global market system. Cambridge, MA: MIT Press.

SDSU. n.d. "Distance education policy." San Diego State University, http://wwwrohan.sdsu.edu/faculty/feenberg/sdsudisted.html.

Slaughter, S. and L. Leslie. 1997. Academic capitalism: Politics, policies, and the entrepreneurial university. Baltimore: Johns Hopkins Univ. Press.

Smith, N. 2002. "Teaching as coaching: Helping students to learn in a technological world." Educause Review (May/June): 38-47

Smith, S.E. 1958. "Educational structure: The English-speaking Canadian universities." In Canada's crisis in higher education, edited by C.T. Bissell. Proceedings from the National Conference of Canadian Universities, 8-22. Ottawa, 12-14 November, 1957. Toronto: Univ. of Toronto Press.

Steeples, C. and C. Jones., eds. 2002. Networked learning: Perspectives and issues. Computer Supported Co-operative Work Series. London: Springer. 
Wallhaus, R.A. 2000. "E-learning: From institutions to providers, from students to learners." In The ' $e$ ' is for everything: E-commerce, e-business and e-learning in the future of higher education, edited by R. Katz and D. Oblinger, 21-52. Educause Leadership Strategies 2. San Francisco: Jossey-Bass, Educause \& Pricewaterhouse Coopers.

WBSI. 1987. "Social Factors in Computer Mediated Communications.” Report prepared for Digital Equipment Corporation. 30 March.

1986. "Proposal for the creation of a computer-mediated social systems research and development program at the Western Behavioural Sciences Institute Jointly with the Digital Equipment Corporation.” Proposal submitted: May, 1986. LaJolla: WBSI.

Werry, C. 2001. "The work of education in the age of E-College." First Monday 6: 5, at http://www.firstmonday.dk/issues/issue6 5/werry/index.html.

White, F. 1999. "Digital diploma mills: A dissenting voice." First Monday 4: 7, at http://www.firstmonday.dk/issues/issue4 7/white/.

Winner, L. 1986. The whale and the reactor. Chicago: Univ. of Chicago Press.

1977. Autonomous technology: Technics-out-of-control as a theme in political thought. Cambridge: MIT Press.

Wulf, W.A. 1998. "University alert: The information railroad is coming." Virginia.edu 2, no. 2, at http://www.itc.virginia.edu/virginia.edu/fall98/mills/comments/c1.html.

Xin, Cindy. 2003. "Towards A Theory of Collaborative Discourse in Computer Conferencing." at http://www.textweaver.org/background.htm.

${ }^{1}$ Contrast this evangelism with the contemporary language of "blended learning" or "instructional enhancement."

${ }^{2}$ It is ironic that when in the mid 1980s the Western Behavioral Sciences Institute invited Peter Drucker to speak to the first online educational program, he had his secretary send back a preprinted card declining the invitation. Apparently, it took a while for this futurologist to see the future and even then his vision turned out to be pretty fuzzy.

${ }^{3}$ Cf. Naidu 2003; Inglis 2002; Smith 2002; Steeples and Jones 2002; Bates 2000; Katz and Oblinger 2000; Duderstadt 1999.

${ }^{4}$ Cf. Moll 2001, 1997; Levidow 2002; Aronowitz 2000; Robins and Webster 1999; Schiller 1999.

${ }^{5}$ Cf. Latour 1999, 1995, 1991; Callon and Latour 1981; Pinch and Bijker 1989; Winner 1986, 1977.

${ }^{6}$ Cf. Cornford and Pollock 2003; Gunawardena and McIsaac 2004; Feenberg 2002, 1999b, 1993; Robins and Webster 2002.

${ }^{7}$ Feenberg 2002, 1999a, 1995, 1991.

${ }^{8}$ Cf. Galan 2001, 18-21.

${ }^{9}$ Documentary material for this section was obtained from the WBSI archive in the Applied Communication and Technology Lab at Simon Fraser University. 
${ }^{10}$ For a more detailed account of the structure and legacy of the SMSS program, see Feenberg 1999b, 1993.

${ }^{11}$ For an account of the relation of communicative and intellectual functions in educational conferencing, see Xin 2003.

${ }^{12}$ Feenberg 2002, 1999, 1995; Latour 1995; Latour and Callon 1981.

${ }^{13} \mathrm{http}: / /$ www.textweaver.org.

${ }_{15}^{14} \mathrm{http}: / / \mathrm{www}$.sakaiproject.org.

${ }^{15}$ Cf., www.aaup.org; www.caut.ca/english.

${ }^{16}$ Cf., http://www-rohan.sdsu.edu/faculty/feenberg/sdsudisted.html. 